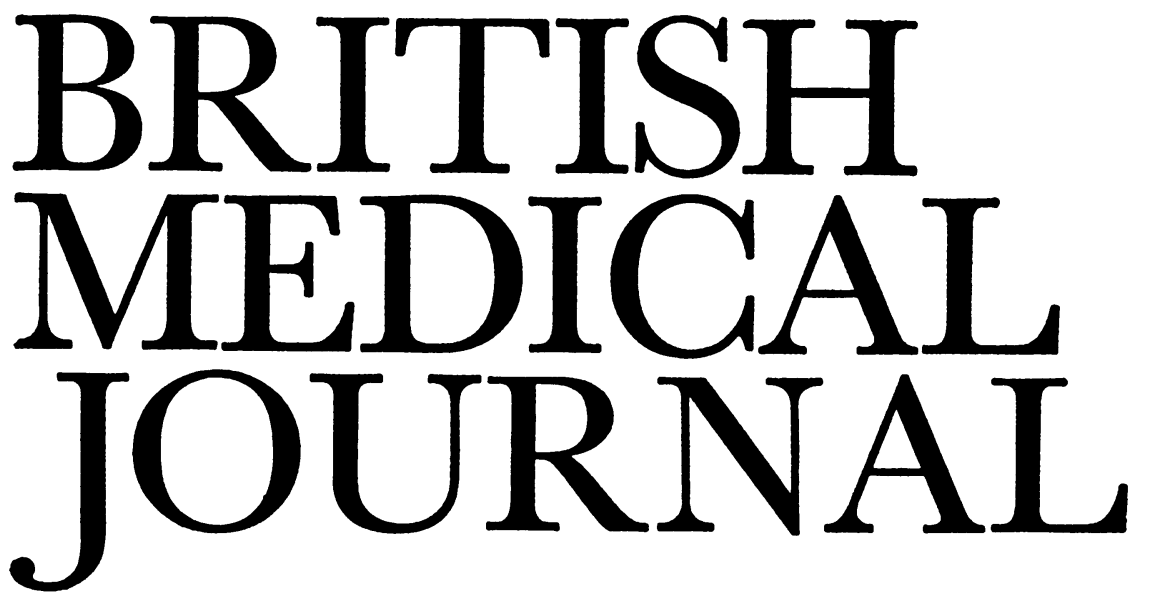

LONDON SATURDAY 16 MARCH 1974

\title{
Facing the Economic Facts
}

Whatever the strength or duration of the new government there is general agreement that there will be no marked increase in material prosperity in Britain for some years to come. Those with money in the bank may be able to live on it; but organizations like the N.H.S. may reasonably ask what their outlook is likely to be in a period of financial stringency.

There is abundant evidence that the Service has been starved of money for years and that staff morale is low as a result. Among doctors, consultants are especially discontented at present, and this week (p. 509) we start publication of a series of "conversations with consultants." Many complain that they have been left behind in comparison with other N.H.S. doctors in terms of pay: indeed consultant salaries have risen only by $71 \%$ in the last ten years compared with $108 \%$ for G.P.s and $150 \%$ for junior hospital staff. ${ }^{1}$ The proposals for a new contract for junior staff, which will give them more time off and payment for duties over a basic minimum of 40 hours, have provoked bitter comment to our reporters from some consultants. Their contract, they stress, is still open-ended and some of them in regional hospitals have been virtually single-handed for years with no suggestion of extra payment in recognition of the hours they are on call. The first shot in a fresh round of negotiation for doctors is the letter from the B.M.A. to the Department of Health printed at p. 524. As it makes clear, since the settlement with the miners there is now "a new situation."

The policy of the Central Manpower Committee is that fewer registrars will be employed in teaching hospitals, ${ }^{2}$ and this combined with the new junior contract may mean that consultants in medical schools will find themselves covering emergency duties. Inevitably such a change will affect research and teaching. For years these consultants have willingly toured the country lecturing on courses and in postgraduate centres, usually for minimal expenses and in their spare time. They will be less willing to do so if they have to cover one night in three so that the Department of Health can avoid paying overtime rates to registrars.

Another potent cause of discontent among medical and nursing staff is the delay and postponement of programmes for rebuilding and upgrading obsolete hospitals. Certainly much has been done in the last decade: but there are still far too many Victorian workhouses in use as hospitals despite their having been scheduled for replacement 20 years ago or more. Throughout the hospital service emergency economies have been made time and again to deal with cuts in government spending and obsolete equipment has been kept in service.

If doctors have been treated badly, many grades of ancillary staff have been treated worse. Few workers in Britain are so badly paid as hospital porters or ward orderlies: little wonder that in the "prosperous southeast" there are countless unfilled vacancies. Nurses, ambulance staff, and physiotherapists are paid at levels well below those offered to comparable staff in private industry; and in some small specialties such as speech therapy the numbers employed by the N.H.S. are acknowledged to be well under half those needed, ${ }^{3}$ but again the money to pay for an adequate service cannot be found.

Too often when criticisms of this kind are made the Government of the day and the Department of Health produce bland statistics to show that each year more money is spent than ever before, and that the numbers of doctors, nurses, and everyone else are rising year by year. So they should. Each year the population grows by the size of a new town the size of Coventry; and each year new techniques and treatments come into use that demand more staff and more resources. In practice the expansion of the N.H.S. has failed to keep abreast of technical developments-and patients die of conditions such as renal failure because dialysis facilities are not available for all of them.

Most of the chronic problems of the N.H.S. could be solved or at least relieved by making more money available. The Government should be honest with the public about the possibilities. Its election manifesto ${ }^{4}$ called for the abolition of prescription charges, the provision of free family planning, and the phasing out of private practice from the hospital service. If these pledges are to be honoured and the necessary additional money found for the N.H.S. then there must be a very large increase in the amount of Government expenditure that goes on health. Such an increase would necessarily imply cuts elsewhere-in defence, for example, or in social services such as unemployment benefit, in road building, or in subsidising projects such as Concorde or Maplin.

This may be politically or economically unacceptable. If so, the only alternative is a drastic revision of the concept of a free N.H.S. High standards of medical care could be preserved by massive cuts in the Service itself: food in hospital or most drugs could be made a charge on patients; or the provision of spectacles, or hearing aids, or dental treatment could be taken out of the N.H.S. (with rebates available from 
the social security system in cases of need). One or other of these alternatives is needed. The last Conservative budget cut health expenditure; ${ }^{5}$ a further effective cut by abolition of prescription charges would accelerate the spiral of economic decline that is already evident. A second-rate service will attract only second-rate recruits and Britain will join the ranks of countries which export their doctors and nurses overseas.

Unpopular decisions can be made at a time of acknowledged economic adversity by a government at the start of its term of office. The electorate is certainly expecting them. What is not acceptable any longer is a bland reassuring attitude at the Department of Health claiming that all is well and the N.H.S. is the envy of Europe. It may have been in the $5 ! \mathrm{s}$-it isn't any more.

\footnotetext{
B.M.A. Press Conference, 5 February 1974.

British Medical Fournal, 1973, 4, 369.

British Medical Journal, 1974, 1, 335.

- British Medical fournal, 1974, 1, 335.

- British Medical fournal, 1974, 1, 47.
}

\section{Pre-eclampsia and the Kidney}

Medical students learn half-a-dozen explanations for preeclampsia, and the theories change from year to year; there are plenty to choose from. ${ }^{1}$ Amid this speculation one mechanism appears well supported by clinical and experimental observations and must be fitted into any aetiological conceptthe role of uteroplacental ischaemia. ${ }^{2}$

Pre-eclampsia is common in first pregnancy, twin and multiple pregnancies, and hydatiform mole, all situations in which the growth of the uteroplacental unit is likely to outstrip the development of an adequate blood supply. It is relieved by bed rest, which prevents the deleterious effects of exercise on uterine blood flow; these are exaggerated in pre-eclampsia. ${ }^{3}$ Arteriography during pregnancy shows that the gravid uterus is supplied by a rich vasculature derived from dilated uterine, ovarian, and other collateral arteries; a much poorer blood supply is visualized in patients with pre-eclampsia. ${ }^{4}$ The well established familial tendency to pre-eclampsia and eclampsia in first pregnancy has not been explained on any vascular basis, but pre-eclampsia in later pregnancies is a predictor of essential hypertension and diabetes. ${ }^{5} 6$ The predisposition of such women and of those with established hypertension, diabetes, and chronic renal disease could be explained by their possession of vessels incapable of the massive dilatation required for normal pregnancy, though this suggestion has not been confirmed experimentally. Impaired placental function, shown by poor fetal growth, reduced excretion of oestrogens, and declining plasma level of placental lactogen are characteristic of late pre-eclampsia and important harbingers of intrauterine death. ${ }^{78}$ The best animal models of pre-eclampsia are pregnant dogs and primates whose uterine blood flow has been reduced by constricting the uterine arteries and severing the collaterals. 910 Uteroplacental ischaemia is clearly the primary event in these animals, and it probably plays the same role in the human disease.

Agreement ends when a link is sought between placental insufficiency and the manifestations of pre-eclampsiaoedema, hypertension, proteinuria, and renal insufficiency. Oedema is common in normal pregnancy, and there is wide overlap between normal and pre-eclamptic women in visible oedema and measured sodium and water retention. ${ }^{11}$ The idea that hypersecretion of aldosterone might be the cause of sodium retention and hypertension was attractive while it lasted; but the plasma concentration of aldosterone is in fact lower in women with pre-eclampsia than in matched controls, ${ }^{12}$ and the occurrence of pre-eclampsia in patients with Addison's disease ${ }^{13}$ makes it unlikely that aldosterone is an essential factor in the disease. There is an astonishing lack of agreement about the effect of sodium restriction, diuretics, and sodium supplements on the course of the disease. ${ }^{2}$

Renin is produced in the chorion ${ }^{14}$ and uterine muscle. ${ }^{15}$ Hypersecretion of uterine or renal renin has been blamed for the hypertension and nephropathy of pre-eclampsia; Sophian ${ }^{1}$ called it "the aetiological factor." Plasma levels of renin, renin substrate, and angiotensin II are, however, no higher in pre-eclampsia than in normal pregnancy and may be lower ${ }^{12}$ except perhaps at the very end of pregnancy. ${ }^{1617}$ It is difficult to blame angiotensin deficiency ${ }^{18}$ for any of the features of pre-eclampsia when plasma angiotensin II levels are not raised above those in normal pregnancy. Pre-eclamptic women have poorly distensible arterioles, ${ }^{19}$ and many of their abnormalities could be explained by a circulating pressor agent other than renin. ${ }^{12}$ Apparently their blood has a pressor effect when retransfused after pregnancy, ${ }^{20}$ though this observation awaits confirmation and comparison with normal pregnancy. The typical sequence of events-hypertension, renal lesions, proteinuria - ${ }^{21}$ is compatible with the possibility that the pressor agent, if any, causes the renal lesion, but other explanations for the nephropathy are more popular.

Proteinuria in pre-eclampsia is of glomerular origin and moderately selective ${ }^{22} 23$ but electron microscopy does not show the changes in podocytes found in most other glomerulonephropathies causing proteinuria, though one description mentions epithelial swelling. ${ }^{24}$ The typical findings are endothelial swelling, obliteration of capillary lumina, subendothelial deposits, and enlargement of mesangial cells. ${ }^{24} 27$ The subendothelial deposits are the most characteristic lesion and are very similar to those which are found in the rabbit after intravacular coagulation. ${ }^{27}$ Fluorescence microscopy shows abundant fibrin in the glomeruli. ${ }^{28}$ This has led to the dominant theory, that the renal lesions are the result of intravascular coagulation caused by some substance released from the damaged placenta. Intravascular coagulation is present in pre-eclampsia ${ }^{29} 31$ and in animal models ${ }^{32}$ as judged by the presence of fibrin degradation products in plasma and urine, low platelet counts, and increased fibrinogen turnover. It may be responsible for the changes in lung function in pre-eclampsia which are reversed by heparin. ${ }^{33}$

An alternative explanation for the renal lesion is suggested this week by Dr. O. M. Petrucco and his colleagues (p. 473). On fluorescence microscopy they have detected IgM and IgG in the glomeruli of pre-eclamptic women, in proportion to the severity of the disease, and found complement in arterioles and sometimes in glomeruli. They suggest that the negative findings reported by previous authors may have been due to lack of specificity in the antisera employed. They suggest that immunological mechanisms may be concerned in the nephropathy of pre-eclampsia and draw analogies with transplant rejection. A number of observations do not readily fit this theory. Serum complement is raised in pregnancy, and pre-eclamptic women are no different from normals. 34 The clinical manifestations and the renal lesion remit rapidly after delivery on a very different time scale from the resolution of, for instance, poststreptococcal glomerulonephritis. However, these conflicts of evidence apply to all current theories, and 